\title{
Endocardial hypothermia and pulmonary vein isolation with epicardial cryoablation in a porcine beating-heart model
}

Saqib Masroor, MD, MHS, ${ }^{a}$ Mary-Ellen Jahnke, RN, ${ }^{a}$ Antoine Carlisle, DVM, ${ }^{\text {a }}$ Catherine Cartier, BSc, MEng, ${ }^{b}$ Jean-Pierre LaLonde, BSME, ${ }^{\mathrm{b}}$ Timothy MacNeil, BS, ${ }^{\mathrm{b}}$ Andre Tremblay, BSME, ${ }^{\mathrm{b}}$ and Fred Clubb, Jr, DVM, PhD

丹 Supplemental material is available online.
From the Department of Cardiothoracic Surgery, ${ }^{\mathrm{a}}$ Hackensack University Medical Center, Hackensack, NJ; Cryocath Technologies, ${ }^{\mathrm{b}}$ Kirkland, Quebec, Canada; and the Department of Veterinary Pathology, ${ }^{\mathrm{c}}$ Texas A \& M University, College Station, Tex.

Read at the Tenth Annual Meeting of the International Society of Minimally Invasive Cardiothoracic Surgery, Rome, Italy, June 7, 2007.

This work was supported by a grant from CryoCath Technologies, Inc, Kirkland, Canada.

Received for publication Sept 13, 2007; revisions received Nov 29, 2007; accepted for publication Dec 4, 2007.

Address for reprints: Saqib Masroor, MD, MHS, FACC, Director of Minimally Invasive and Robotic Cardiac Surgery, Hackensack University Medical Center, 30 Prospect Ave, Hackensack, NJ 07601 (E-mail: smasroor@humed.com).

J Thorac Cardiovasc Surg 2008;135:132733

\section{$0022-5223 / \$ 34.00$}

Copyright $\odot 2008$ by The American Association for Thoracic Surgery

doi:10.1016/j.jtcvs.2007.12.038
Objective: The objective of this study was to investigate whether epicardial cryoablation could achieve sufficient endocardial hypothermia to create transmural lesions leading to acute and sustained pulmonary vein isolation in a normothermic beatingheart model.

Methods: Thirty-five- to 45-kg pigs underwent median sternotomy. Epicardial cryoablation was performed on the right ventricle after insertion of thermocouples. Endocardial temperatures from thermocouples were recorded continuously and correlated with the thickness of the myocardium. Thirteen animals underwent pulmonary vein isolation as a box lesion by using 5-minute epicardial cryoablation. Endocardial temperatures were measured in 5 of these animals. Ten animals survived for 7 or 30 days. Electrical isolation was tested at the time of surgical intervention and again at death. Hearts were removed en bloc and submitted for gross and microscopic examination.

Results: Endocardial temperature varied inversely with tissue thickness, ranging from $-60^{\circ} \mathrm{C}$ in 5-mm-thick tissue to staying unchanged in tissue more than $10 \mathrm{~mm}$ thick. During pulmonary vein isolation, median endocardial temperatures were between $-1{ }^{\circ} \mathrm{C}$ and $-22^{\circ} \mathrm{C}$. Acute electrical isolation was achieved in all 13 animals. All except one of the animals maintained electrical isolation long-term. Histologic analysis revealed transmurality in $89 \%$ of sections, although none of the box lesions were completely transmural.

Conclusion: Epicardial cryoablation can produce long-term pulmonary vein isolation in a beating heart. Dose-response studies demonstrate consistent endocardial hypothermia in tissues up to $7 \mathrm{~mm}$ thick. To our knowledge, this is the first report documenting endocardial hypothermia during epicardial cryoablation. This technology holds promise for performing the complete maze procedure on a beating heart.

$\mathrm{T}$ The development of the maze procedure was a major milestone in the field of arrhythmia surgery. ${ }^{1}$ But despite its excellent results, ${ }^{1-3}$ it was never widely adopted because of its complexity. To simplify the procedure, Cox and others successfully replaced many of the cut-and-sew maze lesions with linear cryoablations. ${ }^{4,5}$ The success of the maze procedure depends on transmural replacement of myocytes (which conduct electricity) by fibrocytes in the scar (which are effective insulators). In this regard cryoablation was particularly attractive to the surgeon because one could visualize the ice ball forming on the surface of the arrested heart, thus ensuring transmurality.

Beating-heart epicardial cryoablation (EC) is, however, considered a poor model for creating transmural lesions. There is a considerable body of evidence that shows that the efficacy of EC is decreased when the cryoprobe is applied on a beating heart with normal cardiac output. ${ }^{6-10}$ However, the size and depth of the cryolesion also depends on a variety of other factors, including the temperature and size of the probe and 


$$
\begin{aligned}
& \text { Abbreviations and Acronyms } \\
& \begin{aligned}
\text { EC } & =\text { epicardial cryoablation } \\
\text { EI } & =\text { electrical isolation } \\
\text { PVI } & =\text { pulmonary vein isolation } \\
\text { SFXL } & =\text { Surgifrost XL } \\
\text { TC } & =\text { thermocouple }
\end{aligned}
\end{aligned}
$$

the duration and number of the freeze/thaw cycles to which the tissue is subjected. ${ }^{11-14}$ With a study design to optimize the ablative potential of cryothermia, this study was conducted to test the following hypotheses: (1) that EC can achieve adequate endocardial hypothermia (for cell killing), (2) that pulmonary vein isolation (PVI) can be performed with EC, and (3) that EC is associated with histologically transmural lesions.

\section{Materials and Methods Experimental Protocol}

Thirteen Yorkshire pigs weighing 35 to $45 \mathrm{~kg}$ were used in this study, 2 in the acute study and 11 in the chronic (long-term) study. All animals received humane care in compliance with the "Guide for the care and use of laboratory animals" (National Academy Press, Washington, DC). After overnight fasting, each animal was premedicated, intubated, anesthetized with $2 \%$ to $4 \%$ isoflurane, and monitored continuously throughout the procedure. Except for the first animal in the study, heparin was not used. No antiarrhythmic agents were used during or after the procedure.

\section{Cryoablation Device}

Surgifrost XL (SFXL; CryoCath Technologies, Inc, Kirkland, Canada) is a newer device similar to the original Surgifrost (SF6) device, which uses argon gas as a refrigerant and is described in detail elsewhere (Fig E1). ${ }^{15}$ It has a 26 -cm malleable shaft followed by a 15 $\mathrm{cm}$ flexible cryoprobe. The probe is covered by a fixed insulating sheath around $270^{\circ}$ degrees of circumference, leaving only $90^{\circ}$ of exposed surface for cryoablation. There is an additional circumferential mobile sheath that can be passed over the probe to change the length of the ablating segment as needed.

\section{Measurement of Endocardial Temperature}

Chromel-constantan thermocouples (TCs; Fig E2) were used to record endocardial temperature. The data were acquired 100 times per second, and the average was recorded once every second on a Daqbook 260 (IOtech, Cleveland, Ohio) by using Daqview version 9.0.3 software (IOtech). The tip of the TC was attached to a 1- to 2-mmlong steel wire at right angles. Each TC was mounted on a 21-gauge needle, which was inserted into the heart. The needle was then withdrawn, leaving the TC inside. The TC was pulled up snug against the endocardial surface - the horizontally oriented wire preventing it from slipping out. Sufficient endocardial hypothermia was defined as a temperature of at least $-3^{\circ} \mathrm{C}$ to $-10^{\circ} \mathrm{C}$, which has been known to be lethal to cells. ${ }^{16}$

In 2 acute animals TCs were inserted along a straight line in the anterior wall of the right ventricle. Linear cryoablation was per- formed on the right ventricle over the TCs (Fig E3). At the end of the experiment, the linear strip of cryoablated right ventricular myocardium and the embedded TCs were excised. The thickness of the myocardium was measured at each TC and recorded against the lowest temperature recorded by that TC.

In 5 animals ( 2 acute and 3 long-term) TCs were inserted into the left atrium at 2 locations after positioning the cryoprobe around the pulmonary veins, as described below. One was placed on the inferior left atrium (between the left inferior and right inferior pulmonary veins) and another in the interatrial groove (between the right superior and right inferior pulmonary veins). The TCs were inserted from one side of the cryoprobe, aiming for a point on the endocardium opposite the center of the cryoprobe.

\section{Surgical Procedure}

The heart was exposed through a median sternotomy, and the pericardium was opened longitudinally. By using blunt dissection, the transverse sinus was accessed between the superior vena cava and the right superior pulmonary vein and the oblique sinus between the inferior vena cava and the right inferior pulmonary vein. A red rubber catheter was introduced from the right side into the transverse sinus and returned through the oblique sinus, thus encircling all 4 pulmonary veins. The tip of the cryoprobe was secured in the distal end of the red rubber catheter. As the rubber catheter was pulled out of the oblique sinus, the probe took its place around the 4 pulmonary veins (Fig E4). The right inferior pulmonary vein was paced at 120 beats/min, with stimulus strength of $1 \mathrm{~mA}$ at $50 \mathrm{~ms}$. A 5-minute cryoablation was started simultaneous with pacing from the pulmonary vein at $15 \mathrm{~mA}$. Electrical isolation (EI) was defined as failure to pace at $15 \mathrm{~mA}$. Once EI was verified, the probe was thawed and removed. The pacing wire was tunneled under the skin, the chest was closed, and the animal was allowed to wake up.

\section{Postoperative Care and Data Collection}

The animals were closely monitored for 48 hours and survived for 7 or 30 days. For euthanasia, the animals were fasted overnight, premedicated, intubated, and anesthetized. The heart was accessed through the previous median sternotomy. The previously placed pacing wire on the right pulmonary vein was used to check for chronic EI. The animal was then killed, and the heart was removed en bloc and fixed in $10 \%$ formalin.

\section{Histologic and Microscopic Analysis}

The hearts were examined for evidence of intra-atrial thrombus and pulmonary vein stenosis. Two- to 4-mm-thick sections were cut, starting from the center of the posterior left atrium and extending radially outward like the spokes of a bicycle wheel. Serial sections were taken in a clockwise direction, thus sampling the entire circumferential cryolesion. Sections were embedded in paraffin, and 2 slides from each section were stained with hematoxylin and eosin, Masson trichrome, or both stains. Qualitative assessment was performed for each slide.

\section{Results}

\section{Tissue Thickness and Endocardial Hypothermia}

During right ventricular EC, tissue thickness was directly related to endocardial temperature (Fig 1). The median lowest endocardial temperature in 5- and 7-mm-thick tissue was 


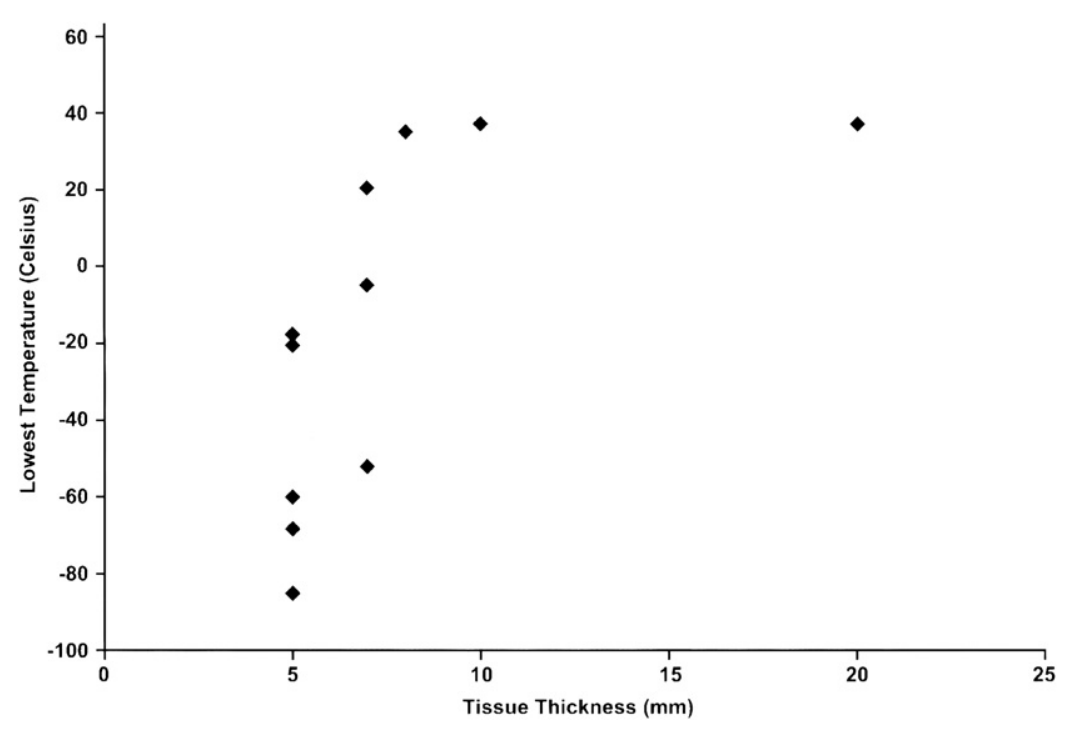

Figure 1. A scatter plot depicting the lowest temperatures reached during epicardial cryoablation of right ventricular myocardium of varying thickness.

$-60^{\circ} \mathrm{C}$ and $-5^{\circ} \mathrm{C}$ (range, $-18^{\circ} \mathrm{C}$ to $-85^{\circ} \mathrm{C}$ and $20^{\circ} \mathrm{C}$ to $-52^{\circ} \mathrm{C}$ ), respectively. A typical dose-response curve is shown in Fig 2. Tissues of $1 \mathrm{~cm}$ or larger remained normothermic throughout. The temperature decrease was rapid between 30 and 60 seconds and then plateaued at 150 to 180 seconds.

\section{Endocardial Hypothermia During PVI}

The median lowest endocardial temperature was $-1{ }^{\circ} \mathrm{C}$ (range, $1^{\circ} \mathrm{C}$ to $-38^{\circ} \mathrm{C}$ ) in the interatrial groove and $-23^{\circ} \mathrm{C}$ (range, $-14^{\circ}$ to $-77^{\circ} \mathrm{C}$ ) in the inferior left atrium. A typical recording of the endocardial temperature is shown in Fig 3.

\section{Operative Results}

PVI was performed successfully in all 13 animals (2 acute and 11 chronic). All chronic animals were neurologically intact after the procedure. The first animal in the long-term study was extubated too early and died of respiratory failure 1 hour later.

\section{Pulmonary Vein Isolation}

PVI consisted of a box lesion, which was completed in most animals as one circumferential lesion. In 4 of the 10 chronic animals, a second EC was performed. In 2 animals there was no EI after the first EC. In another 2 animals circumferential positioning of the cryoprobe resulted in hemodynamic compromise. Therefore 3 sides of the box lesion were created first from the transverse to the oblique sinus, followed by a linear ablation in the interatrial groove, connecting the 2 ends of the first lesion. Acute EI was achieved within 90 to 150 seconds of the start of ablation in animals that required only 1 ablation. In animals requiring 2 ablations, this happened within 90 to 150 seconds of the start of the second ablation.

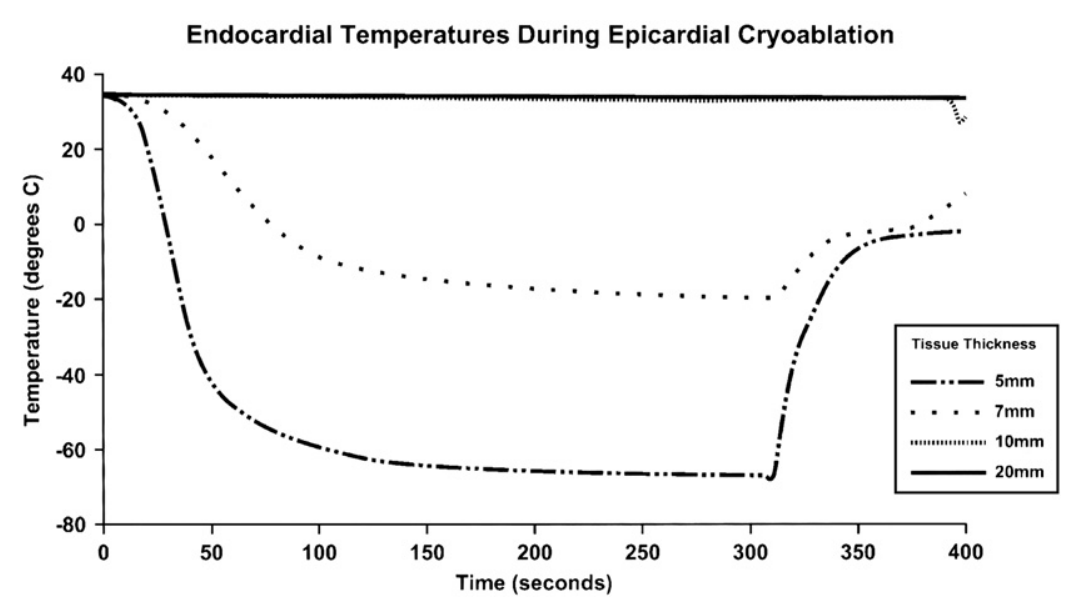

Figure 2. A typical dose-response curve of right ventricular endocardial temperature during 5-minute epicardial cryoablation. 


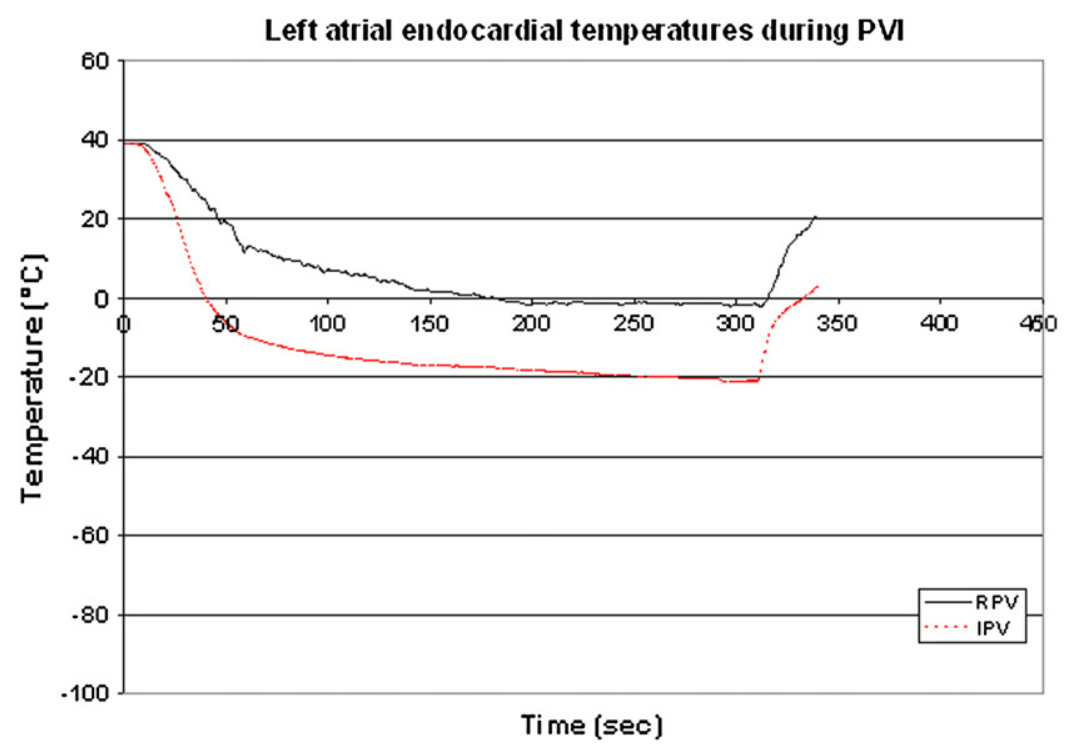

Figure 3. A typical dose-response curve of left atrial endocardial temperature during 5-minute epicardial cryoablation.

\section{Chronic EI}

Of the 10 chronic animals, 2 died at euthanasia before confirmation of EI ( 1 was killed on day 3 because of massive gastrointestinal bleed, and the other was killed as per protocol on day 30). They are, however, included in the histologic analysis. Seven $(87.5 \%)$ of 8 animals demonstrated chronic EI. The one animal that escaped EI had a large lymph node on the roof of the left atrium in the ablation line.

\section{Histology}

Gross examination of the endocardial surface revealed the ablation line as a patchy white line on the outer ostia of the pulmonary veins. The endocardium was smooth and glistening. Thickness varied from 4 to $5.1 \mathrm{~mm}$, with maximum thickness being in the right lateral part of the left atrium. A total of 108 sections were studied. Transmural fibrosis (Fig E5) was seen in $96(89 \%)$ sections, and midmural fibrosis was seen in the remaining 12 sections. Moreover, each animal had at least one nontransmural lesion. The width of the lesion on the epicardial surface varied between 10 and $20 \mathrm{~mm}$.

\section{Discussion}

The use of cryoablation in the treatment of cardiac arrhythmias goes back to $1977,{ }^{17,18}$ when it was first used endocardially to ablate either aberrant atrioventricular conduction pathways or the His bundle for disabling supraventricular tachyarrhythmias. Successful EC was later reported, but that was limited to relatively superficial atrioventricular pathways. ${ }^{7,8,19}$ In some cases of severe cardiac hypertrophy, cryoablation of the His bundle was not successful, even on full cardiopulmonary bypass. Based on this and similar other evidence, there is a general consensus in the scientific commu- nity that EC cannot create transmural lesions in the left atrium in a normothermic beating heart.

However, more recent work has shown that (1) liquid nitrogen at $-150^{\circ} \mathrm{C}$ to $-196^{\circ} \mathrm{C}$ creates larger and deeper lesions than nitrous oxide at $-70^{\circ} \mathrm{C}$; (2) 5 -minute ablations create deeper lesions than 2-minute ablations, and the effect of cryoablation plateaus at around 5 to 6 minutes; (3) multiple ablations can create a lesion larger than a single prolonged ablation; (4) the cell damage is greater if a rapid freeze is followed by a slow thaw; and (5) immediate cell killing is followed by more cell death at the periphery of the cryolesion by apoptosis, with this last effect being more pronounced with a slower thawing process. ${ }^{10-13,20} \mathrm{We}$ therefore hypothesized that the ablative potential of cryothermia can be maximized by using a cooler cryoprobe (reaching $-130^{\circ} \mathrm{C}$ ), longer ablations ( 5 minutes), repeat ablations as needed (rather than 1 prolonged freeze), and a slower thaw (no warm saline to hasten the process). Actual endocardial temperatures were measured for the first time to see whether hypothermia was severe enough to even expect transmurality.

Our results are encouraging. We have demonstrated a very high degree of histologic transmurality, which correlates well with chronic EI. But more importantly, not only was acute EI achieved in all animals, it was also maintained long-term in $88 \%$ of them. The 1 animal that broke through EI at longterm had a lymph node in the ablation line. The increased thickness might have been responsible for the lack of longterm EI. Although a midmural lesion was identified in that animal, it cannot be reliably ascertained whether the midmural lesion was at the site of the lymph node.

These results are at odds with those of Doll and colleagues, ${ }^{15}$ who used a sheep model of EC with the SF6 device. In their report PVI was successful in $25 \%$ of animals 
acutely and in $62.5 \%$ of animals after 2 hours. In thicker tissues of the left and right atrial appendages, only $12 \%$ of animals had EI. Transmurality rates were similarly poor, even though the thickness of the left and right atrial appendages was between 3.2 to $3.8 \mathrm{~mm}$. No endocardial temperatures were measured, and no animals survived long-term.

There are many reasons why there is such a discrepancy between our results. SFXL is a stronger device, with an argon flow rate of $100 \mathrm{~L} / \mathrm{min}$, as opposed to $60 \mathrm{~L} / \mathrm{min}$ in SF6. Doll and colleagues ${ }^{15}$ reported inconsistent probe temperatures of between $-98^{\circ} \mathrm{C}$ to $-160^{\circ} \mathrm{C}$, resulting in a mean of about $-137^{\circ} \mathrm{C}$. With SFXL, probe temperatures were consistently less than $-130^{\circ} \mathrm{C}$ in all animals. Another difference is the fixed insulating sheath in SFXL, which allows cryoablation to proceed predominantly along the exposed $90^{\circ}$ of the probe, thus preventing unnecessary loss of cooling power to adjacent tissues. Consistently lower temperatures might be a reflection of better probe-tissue contact because of the circumferential position of the probe, which tightened like a noose around the 4 pulmonary veins during ablation.

Another difference is the duration and rate of cryoablation. Even though EI was seen earlier in our study, the temperature did not reach a plateau until 150 to 180 seconds. Holman and associates ${ }^{10}$ showed that in human cadaveric hearts the size of the cryolesion continued to increase beyond 5 minutes. Therefore it is unlikely to have transmural lesions when EC is performed for only 2 minutes. Snyder and coworkers ${ }^{21}$ have recently reported that $95 \%$ of mammalian cells lose their viability when exposed to temperatures of less than $-13^{\circ} \mathrm{C}$ for 15 to 60 seconds. In the absence of endocardial temperature measurements, we can only speculate that in the study by Doll and colleagues, ${ }^{15}$ the endocardial cells were not receiving an adequate degree or duration of hypothermia.

Another important factor is the rate of cooling. ${ }^{11}$ SFXL might be causing a bigger cryolesion not just by cooling more but also by cooling faster. In our experiments rapid cooling happened in the first 30 to 60 seconds. SF6, being

Tip of Thermocouple at the tip of the cryolesion, exactly under the probe

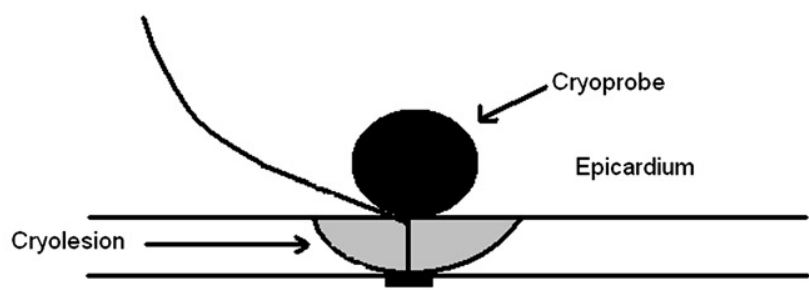

Endocardium a weaker device, might have a lower degree of transmurality because of a slower rate of cooling.

Lastly, the effect of hypothermia can be enhanced by multiple freeze/thaw cycles. This is due to increased thermal conductivity of tissues with repeated cryoablations. The reasons for this are not clear, but they might be related to changes in the cellular structure or the local microperfusion environment during thawing. ${ }^{11}$ The fact that they did not attempt a second ablation might have hampered their ability to achieve transmurality.

One of the reasons Cox used cryoablation was the fact that he could visualize "transmurality" in the form of an ice ball. ${ }^{19}$ Theoretically, at least, this might not necessarily be true. The temperature at the edge of the cryolesion is likely to be $-0.6^{\circ} \mathrm{C}$, which is the freezing point of mammalian tissue. That temperature is still not cold enough because the killing temperature of cells varies between $-3^{\circ} \mathrm{C}$ and $-10^{\circ} \mathrm{C}$, and it might even be lower for a cardiac myocyte. ${ }^{21}$ To our knowledge, this is the first reported study in which actual endocardial temperature was measured during EC.

The right ventricular myocardial temperatures were less than the left atrial temperatures measured during PVI. The reason for this is the way the temperatures were measured in the 2 chambers. During right ventricular ablations, TCs were placed first, followed by cryoablation immediately on top of the TCs, ensuring the near-vertical spatial relationship between the TC and the cryoprobe (Fig 4). During PVI, on the other hand, the probe was positioned first because of the risk of dislodgement of TCs during manipulation of the cryoprobe. The TCs were introduced next from one side of the probe, aiming for a spot on the endocardium exactly opposite the center of the probe. In a beating heart this positioning is not very exact. The TCs could have been a short distance away from the actual tip of the hemispherical cryolesion (Fig 4). The measured endocardial temperature of the left atrium (between $-1{ }^{\circ} \mathrm{C}$ and $-22^{\circ} \mathrm{C}$ ) was likely not that of the tip of the cryolesion, which would have been lower and closer to the right ventricular temperatures.
Tip of thermocouple away from the tip of the cryolesion

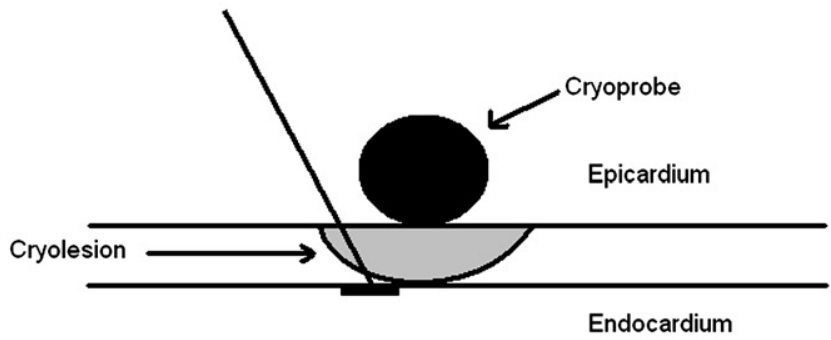

B

Left Atrial Epicardial Cryoablation

Figure 4. A cartoon depicting the possible position of the thermocouple in relation to the tip of the cryoprobe during epicardial cryoablation of the right ventricle (A) versus the left atrium (B; see text). PVI, pulmonary vein isolation. 
The variation in left atrial temperatures between the 2 locations is real. This is because there is no epicardial fat in the inferior part of the left atrium, whereas the interatrial groove has quite a lot of epicardial fat and nerve tissue. The left atrial wall is also thicker in this area. The temperatures would have been closer together had we dissected the interatrial groove more, like during left atriotomy for mitral valve surgery.

These temperature measurements are important from another standpoint. There is always the concern of the damage to red blood cells because of cryoablation. Oeveren and associates $^{22}$ cryoablated blood at $-70^{\circ} \mathrm{C}$ for 60 seconds with a cryocatheter in a closed-loop circuit of blood flowing at 3.5 to $6 \mathrm{~mL} / \mathrm{min}$. Calculating the amount of plasma hemoglobin released, they concluded that a constant small amount of blood cells in the ice ball around the probe $(60 \mu \mathrm{L})$ was being lysed. The remaining blood flowing around the probe was unaffected. By using the same experiments with a radiofrequency catheter, a much larger degree of red cell and platelet damage was seen. Moreover, macroparticles (with a potential for embolism) were seen in circulating blood, which were not seen with cryoablation. In our study the blood is being cryoablated by the endocardial cryoablation line, which can reach temperatures as low as $-60^{\circ} \mathrm{C}$. However, the cryolesion is a hemisphere of 10 to $20 \mathrm{~mm}$ in diameter (the width of the epicardial lesion). Therefore the actual endocardial ablation line is much narrower than $10 \mathrm{~mm}$. With the pulmonary vein and mitral flow velocities in human subjects being 20 to $100 \mathrm{~cm} / \mathrm{s}$ in normal hearts and as low as 10 $\mathrm{cm} / \mathrm{s}$ in dilated hearts in atrial fibrillation, ${ }^{23}$ the number of red cells in contact with the endocardial ablation line at any given time is very small. Damage will be limited to this very small number of red cells and not those flowing past it and is unlikely to be of any clinical significance.

In our study acute EI proved to be a valid procedural end point. Not only was acute EI sustained chronically, it also correlated well with transmurality. Interestingly, each animal had at least 1 section that was nontransmural. The issue of transmurality being a requirement for EI has been questioned by others also. ${ }^{24,25}$ In a recent report, Accord and colleagues ${ }^{24}$ described 3 patients who had undergone successful microwave ablation and had died of unrelated causes. Histologic examination of their hearts revealed 3 of 13 sections being transmural, 7 were midmural, and 3 had no lesion at all. They also reported a mean left atrial wall thickness of 4.3 $\mathrm{mm}$, which falls within the range of thickness seen in our study. Although the reasons for this finding are not the subject of this article, it might be that for energy sources that create wide lesions, such as microwave and cryoablation, the requirement for transmurality is not as stringent as it is for bipolar radiofrequency ablation, which creates very thin discrete lesions. It might also be that transmurality is a surrogate for the "mass of ablated left atrial tissue": the greater the transmurality, the greater the mass of ablated tissue. The question then becomes whether there is a critical mass of atrial tissue that has to be ablated to prevent the left atrium from being able to sustain macroreentrant circuits.

In conclusion, we have demonstrated the following using the current technology: (1) it is possible to produce adequate endocardial hypothermia in myocardium up to 5 to $7 \mathrm{~mm}$ thick, and (2) long-term PVI is possible with beating-heart EC. Its use in human subjects should be considered carefully. Although the thickness of many human left atria will be within this range, ${ }^{24}$ they can sometimes be much thicker, such as in patients with mitral stenosis. Also, it is important to test for EI, which can guide the surgeon if multiple ablations are needed. This study has answered some questions but also questioned some previously known answers, such as the requirement of transmurality for EI. The results of this study give us optimism that it might be possible to perform the complete maze operation by means of EC without using cardiopulmonary bypass.

\section{References}

1. Cox JL, Boineau JP, Schuessler RB, Ferguson TB Jr, Cain ME, Lindsay BD, et al. Successful surgical treatment of atrial fibrillation. JAMA. 1991;266:1976-80.

2. Cox JL, Jaquiss RD, Schuessler RB, Boineau JP. Modification of the maze procedure for atrial flutter and atrial fibrillation. II. Surgical technique of the maze II procedure. J Thorac Cardiovasc Surg. 1995;110: 485-95.

3. Prasad SM, Maniar HS, Camillo CJ, Schuessler RB, Boineau JP, Sundt TM 3rd, et al. The Cox Maze III procedure for atrial fibrillation: long-term efficacy in patients undergoing lone versus concomitant procedures. J Thorac Cardiovasc Surg. 2003;126:1822-8.

4. Ad N, Cox JL. The Maze procedure for the treatment of atrial fibrillation: a minimally invasive approach. J Card Surg. 2004;19:196-200.

5. Nakajima H, Kobayashi J, Bando K, Niwaya K, Tagusari O, Sasako Y, et al. The effect of cryo-maze procedure on early and intermediate term outcome in mitral valve disease: a case matched study. Circulation. 2002;106(suppl 1):I46-50.

6. Guiraudon GM, Klein GJ, Sharma AD. Closed heart technique for Wolff-Parkinson-White syndrome: further experience and potential limitations. Ann Thorac Surg. 1986;42:651-7.

7. Holman WL, Masatoshi I, Douglas JM, Smith PK, Cox JL. Cardiac cryosurgery: effects of myocardial temperature on cryolesion size. Surgery. 1983;93:268-72.

8. Guiraudon GM, Klein GJ, Yee R, Kaushik R, McLellan DG, Cade DM. Surgical epicardial ablation of left ventricular pathway using sling exposure. Ann Thorac Surg. 1990;50:968-71.

9. Bredikis J, Bukauskas F, Zebrauska R, Sakalauskas J, Loschilov V, Nevsky V, et al. Cryosurgical ablation of right parietal and septal accessory atrioventricular connections without the use of extracorporeal circulation. A new surgical technique. J Thorac Cardiovasc Surg. 1985;90: 206-11.

10. Holman WL, Kirklin JK, Anderson PG, Pacifico AD. Variation in cryolesion penetration due to probe size and tissue thermal conductivity. Ann Thorac Surg. 1992;53:123-6.

11. Lustgarten DL, Keane D, Ruskin J. Cryothermal ablation: mechanism of tissue injury and current experience in the treatment of tachyarrhythmias. Prog Cardiovasc Dis. 1999;41:481-98.

12. Ghalili K, Roth JA, Kwan SK, Ferrick K, Fisher JD, Frame R, et al. Comparison of left ventricular cryolesions created by liquid nitrogen and nitrous oxide. J Am Coll Cardiol. 1992;20:1425-9.

13. Misaki T, Allwork SP, Bentall HH. Long-term effects of cryosurgery in the sheep heart. Cardiovasc Res. 1983;17:61-9.

14. Watanabe S, Koyanagi H, Endo M, Yagi Y, Shiikawa A, Kasanuki H. Cryosurgical ablation of accessory atrioventricular pathways without cardiopulmonary bypass: an epicardial approach for Wolff-Parkinson White syndrome. Ann Thorac Surg. 1989;47:257-64. 
15. Doll N, Kornherr P, Aupperle H, Fabricius AM, Kiaii B, Ullmann C, et al. Epicardial treatment of atrial fibrillation using cryoablation in an acute off-pump sheep model. Thorac Cardiovasc Surg. 2003;51:267-73.

16. Mazur P. Cryobiology: the freezing of biological systems. Science. 1970;168:939-49.

17. Gallagher JJ, Sealy WC, Anderson RW, Kasell J, Millar R, Campbell RW, et al. Cryosurgical ablation of accessory atrioventricular connections; am method for correction of the pre-excitation syndrome. Circulation. 1977;55:471-9.

18. Harrison L, Gallagher JJ, Kasell J, Anderson RW, Mikat E, Hackel DB, et al. Cryosurgical ablation of the AV-node-His bundle: a new method for producing A-V block. Circulation. 1977;55:463-70.

19. Cox JL. Intraoperative options for treating atrial fibrillation associated with mitral valve disease. J Thorac Cardiovasc Surg. 2003; 125(suppl):S24-7.

20. Leibo SP, Farrant J, Mazur P, Hanna MG Jr, Smith LH. Effects of freezing on marrow stem cell suspensions: interactions of cooling and warm- ing rates in the presence of PVP, sucrose, or glycerol. Cryobiology. 1970;6:315-32.

21. Snyder KK, Baust JM, Van Buskirk RG, Baust JG. Cardiomyocyte responses to thermal excursions: implications for electrophysiological cardiac mapping. Cell Preservation Technol. 2007;5:116-28.

22. Oeveren WN, Crijns HJGM, Korteling BJ, Wegereef EW, Haan J, Tigchelaar I, et al. Blood damage, platelet and clotting activation during application of radiofrequency or cryoablation catheters: a comparative in vitro study. J Med Eng Technol. 1999;23:20-5.

23. Oh JK, Seward JM, Tajik AJ. Assessment of diastolic function and diastolic heart failure. In: Oh JK, Seward JM, Tajik AJ, eds. The echo manual. 3rd ed. Philadelphia: Lippincott Williams \& Wilkins; 2006:120-42.

24. Accord RE, Van Suyden RJ, Van Brakel TJ, Maessen JC. Post-mortem histologic evaluation of microwave lesions after epicardial pulmonary vein isolation for atrial fibrillation. Ann Thorac Surg. 2005;80:881-7.

25. Smith JM, Hassan M, Ignacio R. Robot-assisted isolation of the pulmonary veins using microwave energy. J Card Surg. 2006;21:83-8.

\section{Interactive eLearning Activities http://learning.ctsnet.org}

The Joint Council on Thoracic Surgery Education was pleased to introduce a series of unique eLearning activities to CTSNet users at the AATS annual meeting in Philadelphia. Sponsored by several cardiothoracic surgical groups, this exciting new educational tool contains narrated videos of actual surgical procedures followed by a series of questions and an evaluation to earn Continuing Medical Education credit.

\footnotetext{
* Diagnosis and Management of Complications of Mitral Valve Repair

* Off Pump Coronary Artery Bypass

* OPCAB Debriefing

* Pediatric Cardiopulmonary Bypass Emergency Situations
}

\section{Experience these new educational tools today and provide us with your feedback. Go to: http://learning.ctsnet.org}

William E. Baumgartner, Chair

Joint Council on Thoracic Surgery Education

Sponsored By:

American Association for Thoracic Surgery

The Society of Thoracic Surgeons

European Association for Cardio-Thoracic Surgery

Children's Memorial Hospital 

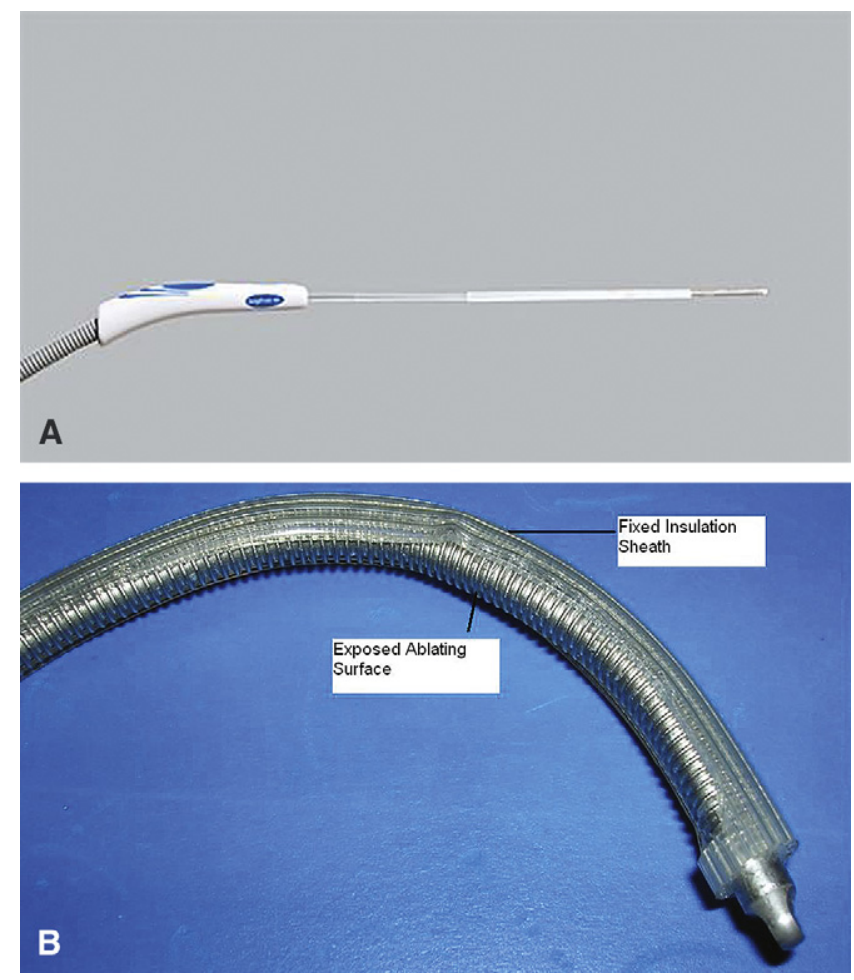

Figure E1. A, Surgifrost XL probe. B, Close-up view of the ablating segment with a fixed sheath covering the outer $270^{\circ}$ circumference. 


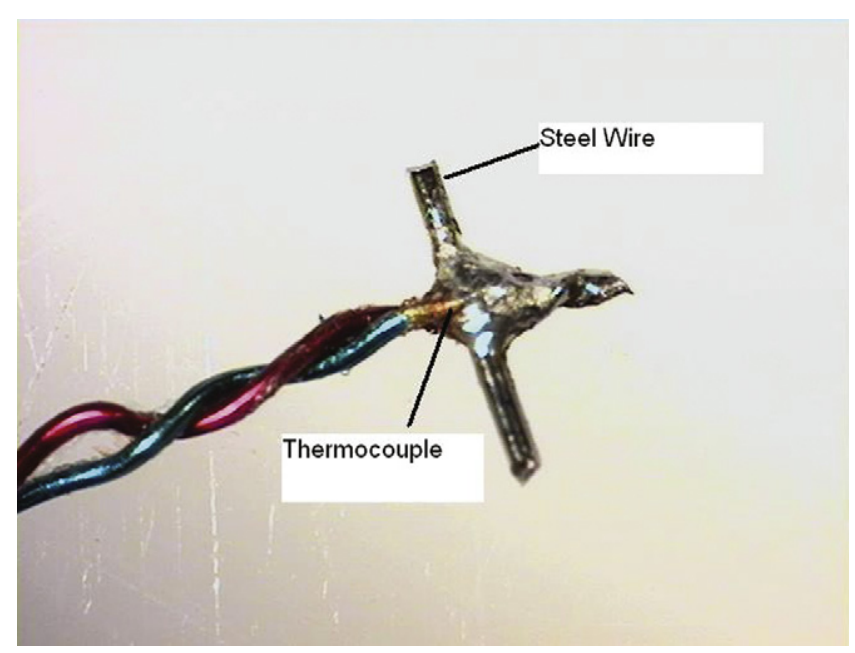

Figure E2. Chromel-constantan thermocouple attached to a horizontally oriented steel wire, which prevents it from slipping out of the heart. 


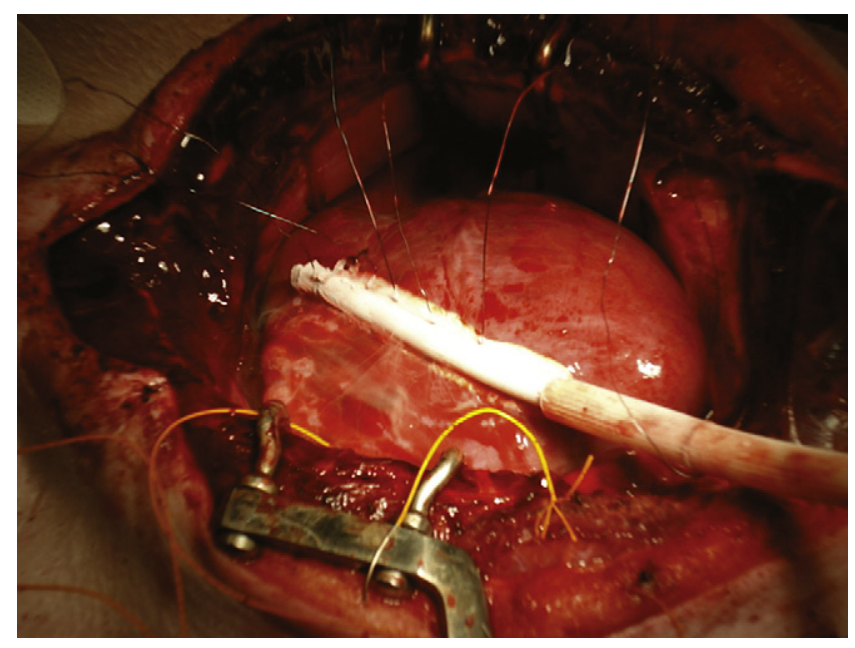

Figure E3. Linear cryoablation over the right ventricle. Thermocouples are seen exiting under the cryoprobe. 


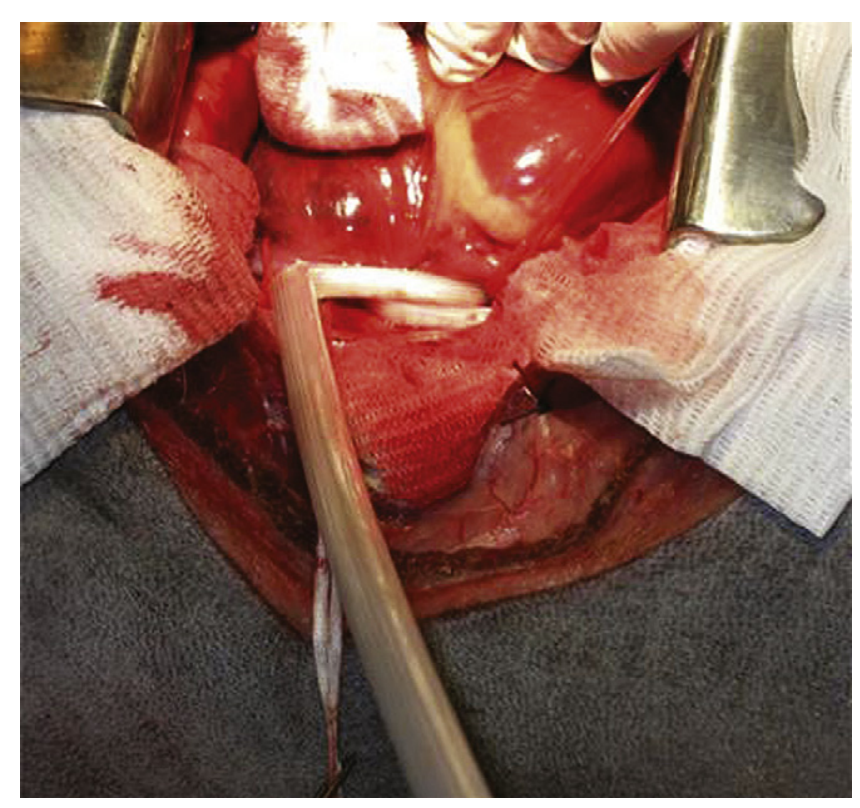

Figure E4. Epicardial cryoablation in progress with the Surgifrost $\mathrm{XL}$ probe tightened around all 4 pulmonary veins. 


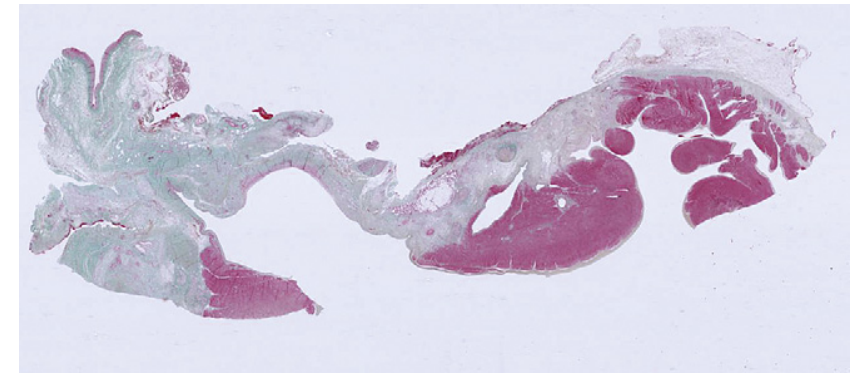

Figure E5. Masson trichrome staining showing a transmural lesion. 